\title{
KELENGKAPAN PENGISIAN DOKUMEN REKAM MEDIS PENYAKIT HERNIA DENGAN METODE ANALISIS KUANTITATIF
}

\author{
Bima Yunus Dzulhanto \\ STIKes Mitra Husada Karanganyar \\ Email: bimayunusd21@gmail.com
}

\begin{abstract}
Based on the result of preliminary survey of patient of diagnosis of Hernia done in RSUD dr.Soediran Mangun Sumarso Wonogiri In the initial survey of 10 documents of medical record of diagnosis of Hernia found the incompleteness in physician name and signature authentication is 3 (30\%) complete while 7 (70\% ) Is not yet fully loaded. The purpose of this research is to know the completeness of filling patient identification, important reporting, autentification and recording document documentation technique of Hernia patient patient. The type of research is descriptive with retrospective approach. The population is Hernia medical record document that amounted to 217 period of year 2016 with big sample of 43 document with sampling technique using simple random sampling, research instrument using checklist and interview guide, observation data collection and unstructured interview and descriptive data analysis. The results of the study showed that the highest incidence of identification of patients by name as much as 20 (46.51\%) and age $21(48.84 \%)$ were on the integrated patient record form, while the medical record number was $22(51,16 \%)$ On the inpatient statement form, the highest incomplete reporting report 1 (2.33\%) is found on the operational and anesthesia report form, the highest incompleteness authentication review based on the name of the doctor / nurse of 20 (46.51\%) is on the summary form Nursing and based on the highest incompleteness physician / nurse signature as much as 16 (37.21\%) are found on the laboratory results form, the review of the highest incorrect recording technique is clear that $9(20.93 \%)$ are found on the nursing care summary form, incorrect The highest error correction of 15 (34.88\%) is on the integrated patient development records form And fixed line assignments are not done correctly as much as 41 (95.35\%) are on the incoming and outgoing summary forms. Based on the result of research, it is suggested that assembling officers should maximize the use of medical record filling sheet to minimize unfilled documents.
\end{abstract}

Keywords : Completeness of Filling, Hernia Patients

\begin{abstract}
ABSTRAK
Berdasarkan hasil survei pendahuluan pasien diagnosis Hernia yang dilakukan di RSUD dr.Soediran Mangun Sumarso Wonogiri Dalam survey awal terhadap 10 dokumen rekam medis diagnosa Hernia ditemukan ketidaklengkapan pada review autentikasi nama dan tanda tangan dokter yaitu $3(30 \%)$ terisi lengkap sedangkan $7(70 \%)$ belum terisi lengkap. Tujuan penelitian adalah mengetahui kelengkapan pengisian identifikasi pasien, pelaoran penting, autentifikasi dan teknik pencatatan dokumen rekam medis pasien rawat inap pasien Hernia. Jenis penelitian adalah deskriptif dengan pendekatan retrospektif. Populasi adalah dokumen rekam medis Hernia yang berjumlah 217 periode tahun 2016 dengan besar sampel sebanyak 43 dokumen dengan teknik pengambilan sampel menggunakan simple random sampling, Instrumen penelitian menggunakan checklist dan pedoman wawancara, pengumpulan data secara observasi dan wawancara tidak terstruktur dan Analisis data secara deskriptif. Hasil penelitian menunjukan bahwa review identifikasi pasien ketidaklengkapan tertinggi berdasarkan nama sebanyak $20(46,51 \%)$ dan umur sebanyak $21(48,84 \%)$ terdapat pada formulir catatan perkembangan pasien terintegrasi, sedangkan nomor rekam medis sebanyak $22(51,16 \%)$ terdapat pada formulir surat pernyataan rawat inap, review pelaporan penting ketidaklengkapan tertinggi sebanyak $1(2,33 \%)$ terdapat pada formulir laporan operasi dan anastesi, review autentikasi ketidaklengkapan berdasarkan nama dokter/ perawat tertinggi sebanyak $20(46,51 \%)$ terdapat pada formulir ringkasan asuhan keperawatan dan berdasarkan tanda tangan dokter/ perawat ketidaklengkapan tertinggi sebanyak $16(37,21 \%)$ terdapat pada formulir hasil laboratorium, review teknik pencatatan yang tidak benar tertinggi jelas
\end{abstract}


terbaca sebanyak $9(20,93 \%)$ terdapat pada formulir ringkasan asuhan keperawatan, tidak benar pembetulan kesalahan tertinggi sebanyak $15(34,88 \%)$ terdapat pada formulir catatan perkembangan pasien terintegrasi dan pemberian garis tetap tidak dilakukan dengan benar sebanyak $41(95,35 \%)$ terdapat pada formulir ringkasan masuk dan keluar. Berdasarkan hasil penelitian, disarankan sebaiknya petugas assembling lebih memaksimalkan penggunaan lembar kelengkapan pengisian catatan medis agar dapat meminimalisir dokumen yang tidak terisi.

\section{Kata kunci : Kelengkapan Pengisian, Pasien Hernia}

\section{PENDAHULUAN}

Berdasarkan 269/MenKes/Per/III/2008 tentang Rekam Medis, adalah berkas yang berisikan catatan dan dokumen tentang identitas pasien, pemeriksaan, pengobatan, tindakan, dan pelayanan lain yang telah diberikan kepada pasien. Penilaian dokumen rekam medis dapat dilakukan dengan cara analisis kuantitatif.

Menurut Sudra (2013) Analisis kuantitatif dokumen rekam medis adalah telaah atau review bagian tertentu dari isi rekam medis dengan maksud menemukan kekurangan khusus yang berkaitan dengan pencatatan rekam medis. Terdapat 5 Review kelengkapan yaitu : review teknik pencatatan, review autentikasi, review pelaporan yang dibutuhkan, review kelengkapan identitas pasien, review kelengkapan lembar formulir sesuai kasus.

Dalam survei awal terhadap 10 dokumen rekam medis diagnosa Hernia pada formulir laboratorium ditemukan ketidaklengkapan pada review autentikasi nama dan tanda tangan dokter yaitu $3(30 \%)$ terisi lengkap sedangkan $7(70 \%)$ belum terisi lengkap. Hal ini akan menyebabkan berkurangnya mutu pelayanan dan terhambatnya pelayanan kepada pasien apabila pengisian pada dokumen tidak lengkap. Berdasarkan latar belakang diatas, maka perlu dilakukan penelitian dengan judul "Kelengkapan Pengisian Dokumen Rekam Medis Penyakit Hernia Dengan Metode Analisis Kuantitatif di RSUD dr. Soediran Mangun Sumarso Wonogiri”. Tujuan umum penelitian Untuk mengetahui kelengkapan pengisian dokumen rekam medis penyakit Hernia dengan metode analisis kuantitatif di RSUD dr. Soediran Mangun Sumarso Wonogiri.

\section{METODE}

Jenis penelitian ini adalah deskriptif. Pendekatan penelitian ini adalah retrospektif dimana dalam penelitian ini menggunakan data lampau pada periode tahun 2016. Penelitian ini dilakukan di RSUD dr. Soediran Mangun Sumarso Wonogiri, pengambilan data dilaksanakan pada bulan Maret 2017. Pada penelitian ini populasinya adalah seluruh dokumen rekam medis pasien rawat inap dengan diagnosis Hernia 217 dokumen rekam medis pada periode tahun 2016. Besar sampel ditentukan dengan mengambil $20 \%$ dari total populasi, teknik pengambilan sampel dengan sistematis non random jadi besar sampel yang digunakan yaitu 43 dokumen rekam medis dengan mengambil 20\% dari 217 populasi kasus hernia pasien rawat inap tahun $2016 \mathrm{di}$ RSUD dr. Soediran Mangun Sumarso Wonogiri. Instrumen yang digunakan dalam pengumpulan data dengan menggunakan Chek list. Cara pengumpulan data dengan melakukan observasi dan wawancara tidak terstruktur dengan memberikan pertanyaan kepada petugas assembling untuk mengetahui faktor yang menyebabkan terjadinya ketidaklengkapan dokumen rekam medis pasien penyakit Hernia. Teknik pengolahan yaitu Collecting (pengumpulan), Editing, Klasifikasi, Tabulating dan Penyajian data. Analisis yang digunakan analisis diskriptif cara menguraikan atau memaparkan hasil penelitian mengenai kelengkapan isi pada dokumen rekam medis degan penyakit Hernia yang di analisis berdasarkan teori yang telah dikemukakan dalam tinjauan pustaka tanpa melakukan uji statistik. 


\section{HASIL}

\section{Kelengkapan Identitas Pasien}

a. Kelengkapan identitas pasien berdasarkan nama pasien

Tabel 1. Kelengkapan identitas pasien berdasarkan nama pasien

\begin{tabular}{llcccccc}
\hline \multirow{2}{*}{ No } & \multicolumn{1}{c}{ Jenis Formulir } & \multicolumn{2}{c}{ Terisi } & \multicolumn{2}{c}{ Tidak Terisi } & \multicolumn{2}{c}{ Total } \\
\cline { 3 - 7 } & & $\mathbf{N}$ & $\mathbf{\%}$ & $\mathbf{N}$ & $\mathbf{\%}$ & $\mathbf{N}$ & $\mathbf{\%}$ \\
\hline 1. & Ringkasan Masuk Keluar & 43 & 100 & 0 & - & 43 & 100 \\
\hline 2. & Resum Pasien Pulang & 41 & 95,35 & 2 & 4,65 & 43 & 100 \\
\hline 3. & Grafik Vital Sign & 43 & 100 & 0 & - & 43 & 100 \\
\hline 4. & $\begin{array}{l}\text { Catatan Perkembangan pasien } \\
\text { terintegrasi }\end{array}$ & 23 & 53,49 & 20 & 46,51 & 43 & 100 \\
\hline 5. & Ringkasan Asuhan Keperawatan & 39 & 90,70 & 4 & 9,30 & 43 & 100 \\
\hline 6. & Hasil Laboratorium & 43 & 100 & 0 & - & 43 & 100 \\
\hline 7. & Surat Persetujuan Tindakan & 43 & 100 & 0 & - & 43 & 100 \\
& Medis & & & & & & \\
\hline 8. & Laporan Operasi & 41 & 95,35 & 2 & 4,65 & 43 & 100 \\
\hline 9. & Laporan Anastesi & 42 & 97,67 & 1 & 2,33 & 43 & 100 \\
\hline 10. & Surat Pernyataan Rawat Inap & 39 & 90,70 & 4 & 9,30 & 43 & 100 \\
\hline
\end{tabular}

Persentase tertinggi tingkat kelengkapan dokumen rekam medis (100\%). Dan persentase pengisian identitas pasien berdasarkan nama ketidaklengkapan tertinggi terdapat pada pasien terdapat pada formulir Ringkasan masuk formulir catatan perkembangan pasien keluar, grafik vital sign, hasil laboratorium dan terintegrasi sebanyak 20 dokumen rekam medis surat persetujuan tindakan medis sebanyak 43 (46,51\%).

b. Kelengkapan identitas pasien berdasarkan nomor RM Tabel 2. Kelengkapan identitas pasien berdasarkan nomor RM

\begin{tabular}{|c|c|c|c|c|c|c|c|}
\hline \multirow[t]{2}{*}{ No } & \multirow[t]{2}{*}{ Jenis Formulir } & \multicolumn{2}{|c|}{ Terisi } & \multicolumn{2}{|c|}{ Tidak Terisi } & \multicolumn{2}{|c|}{ Total } \\
\hline & & $\mathbf{N}$ & $\%$ & $\mathbf{N}$ & $\%$ & $\mathbf{N}$ & $\%$ \\
\hline 1. & Ringkasan Masuk Keluar & 43 & 100 & 0 & - & 43 & 100 \\
\hline 2. & Resum Pasien Pulang & 41 & 95,35 & 2 & 4,65 & 43 & 100 \\
\hline 3. & Grafik Vital Sign & 41 & 95,35 & 2 & 4,65 & 43 & 100 \\
\hline 4. & $\begin{array}{l}\text { Catatan Perkembangan pasien } \\
\text { terintegrasi }\end{array}$ & 26 & 60,47 & 17 & 39,53 & 43 & 100 \\
\hline 5. & Ringkasan Asuhan Keperawatan & 39 & 90,70 & 4 & 9,30 & 43 & 100 \\
\hline 6. & Hasil Laboratorium & 43 & 100 & 0 & - & 43 & 100 \\
\hline 7. & $\begin{array}{l}\text { Surat Persetujuan Tindakan } \\
\text { Medis }\end{array}$ & 39 & 90,70 & 4 & 9,30 & 43 & 100 \\
\hline 8. & Laporan Operasi & 41 & 95,35 & 2 & 4,65 & 43 & 100 \\
\hline 9. & Laporan Anastesi & 42 & 97,67 & 1 & 2,33 & 43 & 100 \\
\hline 10. & Surat Pernyataan Rawat Inap & 21 & 48,84 & 22 & 51,16 & 43 & 100 \\
\hline
\end{tabular}

Persentase tertinggi tingkat kelengkapan dokumen rekam medis (100\%). Dan persentase pengisian identitas pasien berdasarkan nomor ketidaklengkapan tertinggi terdapat pada RM terdapat pada formulir ringkasan masuk formulir Surat Pernyataan Rawat Inap keluar dan hasil laboratorium sebanyak 43 sebanyak 22 dokumen rekam medis $(51,16 \%)$.

c. Kelengkapan identitas pasien berdasarkan umur

Tabel 3. Kelengkapan identitas pasien berdasarkan umur

\begin{tabular}{llcccccc}
\hline \multirow{2}{*}{ No } & Jenis Formulir & \multicolumn{2}{c}{ Terisi } & \multicolumn{2}{c}{ Tidak Terisi } & \multicolumn{2}{c}{ Total } \\
\cline { 3 - 7 } & & $\mathbf{N}$ & $\mathbf{\%}$ & $\mathbf{N}$ & $\mathbf{\%}$ & $\mathbf{N}$ & $\mathbf{\%}$ \\
\hline 1. & Ringkasan Masuk Keluar & 43 & 100 & 0 & - & 43 & 100 \\
\hline 2. & Resume Pasien Pulang & 41 & 95,35 & 2 & 4,65 & 43 & 100 \\
\hline
\end{tabular}




\begin{tabular}{|c|c|c|c|c|c|c|c|}
\hline 3. & Grafik Vital Sign & 42 & 97,67 & 1 & 2,33 & 43 & 10 \\
\hline 4. & $\begin{array}{l}\text { Catatan Perkembangan pasien } \\
\text { terintegrasi }\end{array}$ & 22 & 51,16 & 21 & 48,84 & 43 & 100 \\
\hline 5. & Ringkasan Asuhan Keperawatan & 39 & 90,70 & 4 & 9,30 & 43 & 100 \\
\hline 6. & Hasil Laborator & 43 & 100 & 0 & - & 43 & 0 \\
\hline 7. & $\begin{array}{l}\text { Surat Persetujuan Tindakan } \\
\text { Medis }\end{array}$ & 43 & 100 & 0 & - & 43 & 100 \\
\hline 8. & Laporan Operasi & 41 & 95,35 & 2 & 4,65 & 43 & 100 \\
\hline 9. & Laporan Anastesi & 41 & 95,35 & 2 & 4,65 & 43 & 100 \\
\hline 10. & Surat Pernyataan Rawat Inap & 42 & 97,67 & 1 & 2,33 & 43 & 100 \\
\hline \multicolumn{3}{|c|}{$\begin{array}{l}\text { Persentase tertinggi tingkat kelengkapan } \\
\text { pengisian identitas pasien berdasarkan umur } \\
\text { terdapat pada formulir ringkasan masuk keluar, } \\
\text { hasil laboratorium, dan surat persetujuan } \\
\text { tindakan medis sebanyak } 43 \text { dokumen rekam }\end{array}$} & \multicolumn{5}{|c|}{$\begin{array}{l}\text { medis }(100 \%) . \text { Dan persentas } \\
\text { ketidaklengkapan tertinggi terdapat pac } \\
\text { formulir Catatan perkembangan pasie } \\
\text { terintegrasi sebanyak } 21 \text { dokumen rekam med } \\
(48,84 \%) \text {. }\end{array}$} \\
\hline
\end{tabular}

2. Kelengkapan Pengisian Laporan atau Catatan Penting Berdasarkan Formulir

Tabel 4. Kelengkapan pengisian laporan atau catatan penting berdasarkan formulir

\begin{tabular}{|c|c|c|c|c|c|c|c|}
\hline \multirow[t]{2}{*}{ No } & \multirow[t]{2}{*}{ Jenis Formulir } & \multicolumn{2}{|c|}{ Ada } & \multicolumn{2}{|c|}{ Tidak Ada } & \multicolumn{2}{|c|}{ Total } \\
\hline & & $\mathbf{N}$ & $\%$ & $\mathbf{N}$ & $\%$ & $\mathbf{N}$ & $\%$ \\
\hline 1. & Ringkasan Masuk Keluar & 43 & 100 & 0 & - & 43 & 100 \\
\hline 2. & Resum Pasien Pulang & 43 & 100 & 0 & - & 43 & 100 \\
\hline 3. & Grafik Vital Sign & 43 & 100 & 0 & - & 43 & 100 \\
\hline 4 & $\begin{array}{l}\text { Catatan Perkembangan pasien } \\
\text { terintegrasi }\end{array}$ & 43 & 100 & 0 & - & 43 & 100 \\
\hline 5. & $\begin{array}{l}\text { Ringkasan Asuhan } \\
\text { Keperawatan }\end{array}$ & 43 & 100 & 0 & - & 43 & 100 \\
\hline 6. & Hasil Laboratorium & 43 & 100 & 0 & - & 43 & 100 \\
\hline 7. & $\begin{array}{l}\text { Surat Persetujuan Tindakan } \\
\text { Medis }\end{array}$ & 43 & 100 & 0 & - & 43 & 100 \\
\hline 8. & Laporan Operasi & 42 & 97,67 & 1 & 2,33 & 43 & 100 \\
\hline 9. & Laporan Anastesi & 42 & 97,67 & 1 & 2,33 & 43 & 100 \\
\hline 10. & Surat Pernyataan Rawat Inap & 43 & 100 & 0 & - & 43 & 100 \\
\hline
\end{tabular}

Persentase tertinggi tingkat kelengkapan persetujuan tindakan medis, surat pernyataan formulir pelaporan penting terdapat pada rawat inap sebanyak 43 dokumen rekam medis formulir ringkasan masuk keluar, resume (100\%). Dan persentase ketidaklengkapan pasien pulang, grafik vital sign, catatan tertinggi terdapat pada formulir laporan operasi perkembangan pasien terintegrasi, ringkasan dan laporan anastesi sebanyak 1 dokumen asuhan keperawatan, hasil laboratorium, surat rekam medis $(2,33 \%)$.

\section{Kelengkapan Pengisian Auntentikasi}

a. Kelengkapan Pengisian Autentikasi

Tabel 5. Kelengkapan autentikasi berdasarkan nama Dokter / perawat

\begin{tabular}{lllccccc}
\hline \multirow{2}{*}{ No } & \multicolumn{1}{c}{ Jenis Formulir } & \multicolumn{2}{c}{ Terisi } & \multicolumn{2}{c}{ Tidak Terisi } & \multicolumn{2}{c}{ Total } \\
\cline { 2 - 8 } & & N & $\mathbf{\%}$ & $\mathbf{N}$ & $\mathbf{\%}$ & $\mathbf{N}$ & $\mathbf{\%}$ \\
\hline 1. & Ringkasan Masuk Keluar & 40 & 93,02 & 3 & 6,98 & 43 & 100 \\
\hline 2. & Resume Pasien Pulang & 41 & 95,34 & 2 & 4,65 & 43 & 100 \\
\hline 3. & $\begin{array}{l}\text { Catatan Perkembangan } \\
\text { pasien terintegrasi }\end{array}$ & 42 & 97,67 & 1 & 2,33 & 43 & 100 \\
\hline 4. & $\begin{array}{l}\text { Ringkasan Asuhan } \\
\text { Keperawatan }\end{array}$ & 23 & 53,49 & 20 & 46,51 & 43 & 100 \\
5. & Hasil Laboratorium & 42 & 97,67 & 1 & 2,33 & 43 & 100 \\
\hline 6. & $\begin{array}{l}\text { Surat Persetujuan Tindakan } \\
\text { Medis }\end{array}$ & 37 & 86,05 & 6 & 13,95 & 43 & 100 \\
\hline
\end{tabular}




\begin{tabular}{llllllll}
\hline 7. & Laporan Operasi & 41 & 95,35 & 2 & 4,65 & 43 & 100 \\
\hline 8. & Laporan Anastesi & 40 & 93,02 & 3 & 6,98 & 43 & 100 \\
\hline 9. & $\begin{array}{l}\text { Surat Pernyataan Rawat } \\
\text { Inap }\end{array}$ & 37 & 86,05 & 6 & 13,95 & 43 & 100 \\
\hline
\end{tabular}

Persentase tertinggi tingkat kelengkapan pengisian autentikasi berdasarkan nama dokter / perawat terdapat pada formulir catatan perkembangan pasien terintegrasi dan hasil laboratorium sebanyak 42 dokumen rekam

b. Kelengkapan pengisian autentikasi

Tabel 6. Kelengkapan autentikasi berdasarkan tanda tangan Dokter / perawat

\begin{tabular}{|c|c|c|c|c|c|c|c|}
\hline \multirow[t]{2}{*}{ No } & \multirow[t]{2}{*}{ Jenis Formulir } & \multicolumn{2}{|c|}{ Terisi } & \multicolumn{2}{|c|}{$\begin{array}{l}\text { Tidak } \\
\text { Terisi }\end{array}$} & \multicolumn{2}{|c|}{ Total } \\
\hline & & $\mathbf{N}$ & $\%$ & $\mathbf{N}$ & $\%$ & $\mathbf{N}$ & $\%$ \\
\hline 1. & Ringkasan Masuk Keluar & 40 & 93,02 & 3 & 6,98 & 43 & 100 \\
\hline 2. & Resum Pasien Pulang & 43 & 100 & 0 & - & 43 & 100 \\
\hline 3. & $\begin{array}{l}\text { Catatan Perkembangan pasien } \\
\text { terintegrasi }\end{array}$ & 42 & 97,67 & 1 & 2,33 & 43 & 100 \\
\hline 4. & $\begin{array}{l}\text { Ringkasan Asuhan } \\
\text { Keperawatan }\end{array}$ & 29 & 67,44 & 14 & 32,56 & 43 & 100 \\
\hline 5. & Hasil Laboratorium & 27 & 62,79 & 16 & 37,21 & 43 & 100 \\
\hline 6. & $\begin{array}{l}\text { Surat Persetujuan Tindakan } \\
\text { Medis }\end{array}$ & 37 & 86,05 & 6 & 13,95 & 43 & 100 \\
\hline 7. & Laporan Operasi & 39 & 90,70 & 4 & 9,30 & 43 & 100 \\
\hline 8. & Laporan Anastesi & 33 & 76,74 & 10 & 23,26 & 43 & 100 \\
\hline 9. & Surat Pernyataan Rawat Inap & 42 & 97,67 & 1 & 2,33 & 43 & 100 \\
\hline
\end{tabular}

persentase tertinggi tingkat kelengkapan pengisian autentikasi berdasarkan tanda tangan dokter / perawat terdapat pada formulir resume pasien pulang sebanyak 43 dokumen rekam medis (97,67\%). Dan persentase ketidaklengkapan tertinggi terdapat pada formulir ringkasan asuhan keperawatan sebanyak 20 dokumen rekam medis $(46,51 \%)$.

\section{Pencatatan atau Pendokumentasian}

a. Pencatatan atau pendokumentasian berdasarkan jelas terbaca

Tabel. 7 pencatatan atau pendokumentasian berdasarkan jelas terbaca

\begin{tabular}{clcccccc}
\hline \multirow{2}{*}{ No } & \multicolumn{1}{c}{ Jenis Formulir } & \multicolumn{2}{c}{ Benar } & \multicolumn{2}{c}{ Tidak Benar } & \multicolumn{2}{c}{ Total } \\
\cline { 2 - 7 } & & $\mathbf{N}$ & $\mathbf{\%}$ & $\mathbf{N}$ & $\mathbf{\%}$ & $\mathbf{N}$ & $\mathbf{\%}$ \\
\hline 1. & Ringkasan Masuk Keluar & 41 & 95,35 & 2 & 4,65 & 43 & 100 \\
\hline 2. & Resum Pasien Pulang & 39 & 90,70 & 4 & 9,30 & 43 & 100 \\
\hline 3. & Grafik Vital Sign & 40 & 93,02 & 3 & 6,98 & 43 & 100 \\
\hline 4. & Catatan Perkembangan pasien & 40 & 93,02 & 3 & 6,98 & 43 & 100 \\
& terintegrasi & & & & & & \\
\hline 5. & Ringkasan Asuhan & 34 & 79,07 & 9 & 20,93 & 43 & 100 \\
& Keperawatan & & & & & & \\
\hline 6. & Hasil Laboratorium & 43 & 100 & 0 & - & 43 & 100 \\
\hline 7. & Surat Persetujuan Tindakan & 43 & 100 & 0 & - & 43 & 100 \\
& Medis & & & & & & \\
\hline 8. & Laporan Operasi & 36 & 83,72 & 7 & 16,28 & 43 & 100 \\
9. & Laporan Anastesi & 39 & 90,70 & 4 & 9,30 & 43 & 100 \\
10. & Surat Pernyataan Rawat Inap & 43 & 100 & 0 & - & 43 & 100 \\
\hline
\end{tabular}

persentase tertinggi tingkat kelengkapan laboratorium, surat persetujuan tindakan medis Pencatatan atau pendokumentasian berdasarkan dan surat pernyataan rawat inap sebanyak 43 jelas terbaca terdapat pada formulir hasil dokumen rekam medis (100\%). Dan persentase 
ketidaklengkapan tertinggi terdapat pada sebanyak 9 dokumen rekam medis $(20,93 \%)$. formulir ringkasan asuhan keperawatan

b. Pencatatan atau pendokumentasian berdasarkan pembetulan kesalahan

Tabel. 8 Pencatatan atau pendokumentasian berdasarkan pembetulan kesalahan.

\begin{tabular}{|c|c|c|c|c|c|c|c|}
\hline \multirow[t]{2}{*}{ No } & \multirow[t]{2}{*}{ Jenis Formulir } & \multicolumn{2}{|c|}{ Benar } & \multicolumn{2}{|c|}{ Tidak Benar } & \multicolumn{2}{|c|}{ Total } \\
\hline & & $\mathbf{N}$ & $\%$ & $\mathbf{N}$ & $\%$ & $\mathbf{N}$ & $\%$ \\
\hline 1. & Ringkasan Masuk Keluar & 39 & 90,70 & 4 & 9,30 & 43 & 100 \\
\hline 2. & Resum Pasien Pulang & 40 & 93,02 & 3 & 6,98 & 43 & 100 \\
\hline 3. & Grafik Vital Sign & 40 & 93,02 & 3 & 6,98 & 43 & 100 \\
\hline 4. & $\begin{array}{l}\text { Catatan Perkembangan pasien } \\
\text { terintegrasi }\end{array}$ & 28 & 65,11 & 15 & 34,88 & 43 & 100 \\
\hline 5 . & $\begin{array}{l}\text { Ringkasan Asuhan } \\
\text { Keperawatan }\end{array}$ & 36 & 83,72 & 7 & 16,28 & 43 & 100 \\
\hline 6. & Hasil Laboratorium & 43 & 100 & 0 & - & 43 & 100 \\
\hline 7. & $\begin{array}{l}\text { Surat Persetujuan Tindakan } \\
\text { Medis }\end{array}$ & 41 & 95,35 & 2 & 4,65 & 43 & 100 \\
\hline 8. & Laporan Operasi & 35 & 81,40 & 8 & 18,60 & 43 & 100 \\
\hline 9. & Laporan Anastesi & 40 & 93,02 & 3 & 6,98 & 43 & 100 \\
\hline 10. & Surat Pernyataan Rawat Inap & 43 & 100 & 0 & - & 43 & 100 \\
\hline
\end{tabular}

pencatatan atau pendokumentasian dilakukan dengan tidak benar tertinggi pada formulir dengan benar $43(100 \%)$ terdapat pada formulir catatan perkembangan pasien terintegrasi hasil laboratorium dan surat pernyataan rawat sebanyak 15 (34,88\%) dokumen rekam medis.

inap. Dan sedangkan pencatatan dilakukan

c. Pencatatan atau pendokumentasian berdasarkan pemberian garis tetap

Tabel. 9 Pencatatan atau pendokumentasian berdasarkan pemberian garis tetap

\begin{tabular}{llrrrrrr}
\hline \multirow{2}{*}{ No } & \multicolumn{1}{c}{ Jenis Formulir } & \multicolumn{3}{c}{ Benar } & \multicolumn{2}{c}{ Tidak Benar } & \multicolumn{2}{c}{ Total } \\
\cline { 3 - 8 } & & $\mathbf{N}$ & $\mathbf{\%}$ & $\mathbf{N}$ & $\mathbf{\%}$ & $\mathbf{N}$ & $\mathbf{\%}$ \\
\hline 1. & Ringkasan Masuk Keluar & 12 & 4,65 & 41 & 95,35 & 43 & 100 \\
\hline 2. & Resum Pasien Pulang & 41 & 95,35 & 2 & 4,65 & 43 & 100 \\
\hline 3. & $\begin{array}{l}\text { Catatan Perkembangan pasien } \\
\text { terintegrasi }\end{array}$ & & & & & & \\
\hline 4. & Ringkasan Asuhan Keperawatan & 15 & 34,88 & 28 & 65,12 & 43 & 100 \\
\hline 5. & Surat Persetujuan Tindakan medis & 35 & 81,39 & 8 & 18,10 & 43 & 100
\end{tabular}

\begin{tabular}{llrrrrrr}
\hline 6. & Laporan Operasi & 15 & 34,88 & 28 & 65,12 & 43 & 100 \\
\hline 7. & Laporan Anastesi & 10 & 23,26 & 33 & 76,74 & 43 & 100 \\
\hline 8. & Surat Pernyataan Rawat Inap & 14 & 32,56 & 29 & 67,44 & 43 & 100 \\
\hline persentase tertinggi tingkat pencatatan atau & dokumen rekam medis & $\begin{array}{l}(95,35 \%) . \\
\text { Dan }\end{array}$ \\
pendokumentasian berdasarkan pemberian \\
garis tetap terdapat pada formulir catatan \\
perkembangan pasien terintegrasi sebanyak 41
\end{tabular}

\section{PEMBAHASAN}

\section{Kelengkapan Identitas Pasien}

Berdasarkan : Nama Pasien

Menunjukkan bahwa jumlah persentase

tertinggi tingkat kelengkapan pengisian identitas pasien berdasarkan nama pasien terdapat pada formulir Ringkasan masuk keluar, grafik vital sign, hasil laboratorium dan surat persetujuan tindakan medis sebanyak 43 $(100 \%)$ dokumen rekam medis. Menurut Sudra RI (2013) bahwa identitas pasien minimal 
terdiri dari nama pasien dan nomor rekam medis. Identitas berfungsi apabila ada yang hilang atau tercecer maka petugas akan mudah untuk mengidentifikasinya. Persentase ketidaklengkapan tertinggi terdapat pada formulir catatan perkembangan pasien terintegrasi sebanyak $20(46,51 \%)$ dokumen rekam medis. Berdasarkan wawancara dengan petugas assembling, ketidaklengkapan pengisian nama pasien disebabkan oleh petugas yang kurang teliti dalam pengisiannya dan petugas juga kehabisan label pendaftaran rawat inap yang harusnya ada pada formulir ringkasan masuk keluar, resume pasien pulang, grafik vital sign, catatan perkembangan pasien terintegrasi, ringkasan asuhan keperawatan, surat persetujuan tindakan medis, surat pernyataan rawat inap sedangkan untuk formulir laporan operasi dan laporan anastesi dari intasalasi bedah sentral, tetapi pada formulir catatan perkembangan pasien terintergasi terdapat lebih dari 1 formulir yang harus diberi label atau ditulis manual sehingga ada formulir yang tidak kebagian label yang menyebabkan ketidaklengapan. Hal ini belum sesuai dengan prosedur yang tercantum dalam SPO Nomor Dokumen 021/01/001 tentang meneliti kelengakapan dokumen review identifikasi rekam medis minimal nama pasien dan nomor rekam medis.

\section{Kelengkapan Nomor Rekam Medis}

Menunjukkan bahwa jumlah persentase tertinggi tingkat kelengkapan pengisian identitas pasien berdasarkan nomor RM terdapat pada formulir ringkasan masuk keluar dan hasil laboratorium sebanyak $43(100 \%)$ dokumen rekam medis. Menurut Sudra RI (2013) yaitu setiap lembar berkas rekam medis wajib mencantumkan identitas pasien, minimal terdiri dari nama pasien dan nomor rekam medis.

Persentase ketidaklengkapan tertinggi terdapat pada formulir Surat Pernyataan Rawat Inap sebanyak $22(51,16 \%)$ dokumen rekam medis. Berdasarkan hasil wawancara dengan petugas assembling ketidaklengkapan pengisian nomor rekam medis dikarenakan ada yang ditulis manual dan kurang teliti saat pengisiannya sehingga pada item nomor rekam medis ada yang tidak terisi, sedangkan hal ini akan berdampak jika terdapat salah satu formulir yang lepas dari dokumen rekam medis maka petugas akan kesulitan melakukan identifikasi dan penggabungan ke dalam dokumen rekam medis tersebut, sebab nomor rekam medis merupakan identitas khusus bagi pasien.

Kelengkapan Umur Pasien menunjukkan persentase ketidaklengkapan item umur tertinggi terdapat pada formulir Catatan perkembangan pasien terintegrasi sebanyak 21 $(48,84 \%)$ dokumen rekam medis. Berdasarkan hasil wawancara dengan petugas assembling ketidaklengkapan pengisian umur pasien disebabkan karena kehabisan label dan diisi secara manual oleh petugas, karena kurang hati-hati terdapat item umur yang belum diisi. Hal tersebut belum sesuai dengan Standar Pelayanan Minimal Rumah Sakit Kelengkapan Pengisian Dokumen Rekam Medis dengan target kelengkapan $100 \%$. Item umur berfungsi untuk menggolongkan pasien ke poli yang akan dituju berdasarkan usianya. Menurut hasil penelitian Heriyanto (2011) menyatakan jika item umur tidak terisi akan berdampak terhadap kurangnya informasi yang dibutuhkan untuk pelayanan medis yang akan diberikan.

\section{Kelengkapan Pengisian Pelaporan Penting Berdasarkan Jenis Formulir}

Menunjukkan bahwa jumlah persentase tertinggi tingkat kelengkapan formulir pelaporan penting terdapat pada formulir terdapat pada ringkasan masuk keluar, resume pasien pulang, grafik vital sign, catatan perkembangan pasien terintegrasi, ringkasan asuhan keperawatan, hasil laboratorium, surat persetujuan tindakan medis, surat pernyataan rawat inap sebanyak 43 (100\%) dokumen rekam medis. Dokumen rekam medis dengan kasus Hernia formulirnya sudah lengkap semua dan sudah sesuai dengan Sudra RI (2013) tentang Review kelengkapan lembar formulir yang menyatakan petugas melakukan pengecekan terhadap ada tidaknya lembar-lembar formulir rekam medis sesuai dengan kasus tiap pasien.

Persentase ketidaklengkapan tertinggi terdapat pada formulir laporan operasi dan laporan anastesi sebanyak 1 (2,33\%) dokumen rekam medis. Ketidaklengkapan tersebut dikarenakan formulir operasi dan anastesi dari Instalasi Bedah Sentral (IBS), dan setelah dilakukan operasi petugas Instalasi Bedah Sentral kurang teliti dalam memberi formulir sehingga ada 1 dokumen yang tidak lengkap pada formulir laporan operasi. Hal ini belum sesuai PerMenKes No269/Menkes/Per/III/2008 (Bab III tata penyelenggara) pasal 5: rekem medis sebagaimana di maksud pada ayat ( 1 ) 
bahwa Laporan operasi keterangan tetulis di lembar formulir dalam rekam medis, yang diisi oleh dokter setelah melakukan tindakan badah. Laporan operasi harus di isi dengan lengkap berdasarkan harus dibuat segera dan dilengkapi setelah pasien menerima pelayanan.

\section{Kelengkapan Pengisian Auntentikasi}

Kelengkapan Nama Dokter / Perawat

Ketidaklengkapan tertinggi terdapat pada formulir ringkasan asuhan keperawatan sebanyak $20(46,51 \%)$ dokumen rekam medis. Berdasarkan hasil wawancara dengan petugas assembling ketidaklengkapan pengisian nama dokter / perawat disebabkan karena dokter berfokus pada diagnosis sehingga lupa mengisi kelengkapan item nama dokumen rekam medis. Hal ini belum sesuain dengan prosedur SPO Nomor Dokumen 021/01/001 tentang meneliti kelengkapan autentikasi minimal ada nama, tanda tangan, inisial dokter. Nama terang berfungsi untuk mengetahui dokter atau perawat yang menangani pasien, jika masih ditemukan maka dokter/perawat akan diberikan ceklist tidak lengkap dan setiap hari rabu dibuat laporan jumlah ketidaklengkapan kemudian diberikan kepada kepala RM agar dokter/perawat segera melengkapi dokumen rekam medis. Menurut hasil penelitian Wahyu (2011) menyatakan bahwa ketidaklengkapan nama dokter akan berdampak pada dokumen rekam medis tidak bisa dijadikan bukti otentik di pengadilan.

Kelengkapan Tanda Tangan Dokter / Perawat

Persentase ketidaklengkapan tertinggi terdapat pada formulir hasil laboratorium sebanyak 16 (37,21\%) dokumen rekam medis. Berdasarkan hasil wawancara dengan petugas assembling ketidaklengkapan pengisian tanda tangan dokter / perawat kurang teliti dalam pengisianya hal ini akan mengakibatkan petugas rekam medis kesulitan dalam menentukan dokter / perawat yang bertanggung jawab terhadap tindakan medis yang diberikan kepada pasien, menurut teori Sudra RI (2013) bahwa manfaat dan penggunaan rekam medis berdasarkan aspek legal, rekam medis digunakan sebagai bukti telah terjadinya proses pelayanan kesehatan. Rekam medis akan dihadirkan dalam proses persidangan untuk menyelesaikan kasus mediko-legal (kasus medis bermuatan hukum) guna menelusuri kembali kejadian suatu pelayanan kesehatan melalui runtutan "cerita" yang tercatat / terekam didalamnya. Itulah sebabnya maka rekam medis harus segera dibuat setelah melakukan pelayanan kesehatan. Konsep "Tulis yang dilakukan dan lakukan yang ditulis" merupakan salah satu kunci agar rekam medis dapat melaksanakan fungsi legal / hukumnya.

\section{Teknik Pencatatan atau Pendokumentasian}

Berdasarkan analisis kelengkapan dokumen rekam medis di RSUD dr. Soediran Mangun Sumarso Wonogiri disebutkan bahwa kelengkapan dokumen rekam medis untuk review teknik pencatatan, dokter / perawat / bidan petugas medis / tenaga kesehatan lainnya harus menulis dokumen rekam medis dengan tepat, cermat, jelas dan benar. Kesalahan penulisan dapat diperbaiki saat itu juga dengan mencoret yang salah dan dibubuhi paraf, sedangkan penghapusan dengan cara apapun / cairan penghapus tidak diperbolehkan. Berikut hasil analisisnya:

Kelengkapan Pendokumentasian Penulisan Jelas Terbaca

Menunjukkan bahwa jumlah persentase benar tertinggi Pencatatan atau pendokumentasian berdasarkan jelas terbaca terdapat pada formulir hasil laboratorium, surat persetujuan tindakan medis dan surat pernyataan rawat inap sebanyak 43 (100\%) dokumen rekam medis.

Persentase tidak benar tertinggi terdapat pada formulir ringkasan asuhan keperawatan sebanyak 9 (20,93\%) dokumen rekam medis. Berdasarkan wawancara dengan petugas assembling hal ini terjadi karena belum adanya SPO rumah sakit yang mengatur penulisan jelas terbaca. Menurut Sudra RI (2013) bahwa review teknik pencatatan diantaranya memenuhi aspek-aspek antara lain tulisan harus bisa dibaca kembali dengan selayaknya dan tidak menimbulkan kesulitan atau bias persepsi tulisan harus ditulis dengan menggunakan tinta permanen dan berwarna hitam sehingga tidak mudah luntur atau hilang, penulisan hendaknya menggunakan istilah, singkatan, dan simbol yang baku, terdaftar dan terstandar sehingga, bisa dipahami dengan jelas dan pasti oleh pembaca.

Kelengkapan Pendokumentasian Pembetulan kesalahan

Menunjukkan bahwa jumlah persentase benar tertinggi Pencatatan atau pendokumentasian berdasarkan pembetulan kesalahan terdapat pada formulir laporan 
laboratorium dan surat pernyataan rawat inap sebanyak $43(100 \%)$ dokumen rekam medis.

Persentase tidak benar tertinggi terdapat pada formulir catatan perkembangan pasien terintegrasi sebanyak $15(34,88 \%)$ dokumen rekam medis. Pembetulan kesalahan dikarenakan kurangnya sosialisasi kepada dokter/perawat tentang cara pembetulan pencatatan yang salah, yang tidak sesuai diantaranya menggunakan cairan penghapus untuk membetulkan, mencoret lebih dari satu garis pada tulisan yang salah sehingga tulisan tidak dapat dibaca dan tidak dibubuhi paraf saat melakukan pembetulan agar mudah ditelusuri siapa yang melakukan pembetulan tersebut. Hal ini belum sesuai dengan prosedur SPO Nomor Dokumen 021/01/001 tentang meneliti pencatatan tidak ada tipe-ex atau dihapus, ada paraf apabila ada perubahan. Menurut Sudra RI (2013) jika terjadi kesalahan tulisan maka untuk memperbaikinya tidak boleh menyebabkan tulisan yang salah tersebut hilang atau tidak terbaca lagi. Secara umum dianjurkan mencoret satu kali pada tulisan yang salah, menulis perbaikan di atas tulisan yang salah dan mencatumkan tanggal dan tanda tangan yang memperbaiki tulisan tersebut.

Kelengkapan Pendokumentasian Pemberian Garis Tetap

Menunjukkan bahwa jumlah persentase benar tertinggi Pencatatan atau pendokumentasian berdasarkan pemberian garis tetap terdapat pada formulir catatan perkembangan pasien terintegrasi sebanyak 41 $(95,35 \%)$ dokumen rekam medis.

Sedangkan persentase tidak benar tertinggi terdapat pada formulir ringkasan masuk keluar sebanyak 41 (95,35\%) dokumen rekam medis. Kesalahan pemberian garis tetap ini terjadi karena dokter / perawat tidak memberikan garis tetap (-) pada item seperti jenis anastesi, infeksi nosokomial, gol darah, penyebab infeksi, transfusi darah, pengobatan radioterapi dan imunisasi yang diperoleh selama dirawat. Berdasarkan hasil wawancara dengan petugas assembling untuk ketidaklengkapan terjadi karena belum adanya SPO rumah sakit yang mengatur pemberian garis tetap. Menurut Sudra RI (2013) bahwa sisa area kosong pada baris, kolom atau halaman rekam medis dianjurkan untuk "ditutup" dengan tanda coretan garis tengah, horizontal, diagonal atau zigzag. Hal ini untuk mencegah agar tidak terjadi penambahan isi yang tidak semestinya.

\section{SIMPULAN}

1. Pengisian identifikasi pasien lengkap $100 \%$ (43) pada semua formulir DRM Hernia kecuali pada formulir catatan perkembangan pasien terintegrasi sebanyak $20(46,51 \%)$.

2. Pengisian pelaporan penting lengkap $100 \%$ (43) pada semua formulir DRM Hernia kecuali pada formulir laporan operasi dan laporan anastesi sebanyak $1(2,33 \%)$.

3. Pengisian autentifikasi lengkap 20 $(46,51 \%)$ pada formulir ringkasan asuhan keperawatan kecuali pada formulir hasil laboratorium sebanyak $16(37,21 \%)$.

4. Pengisian pendokumentasian yang benar lengkap $100 \%$ (43) pada semua formulir DRM Hernia kecuali pada pemberian garis tetap tidak dilakukan secara benar terdapat pada formulir ringkasan masuk keluar 41 $(95,35 \%)$

\section{DAFTAR PUSTAKA}

Departemen Kesehatan Repubik Indonesia. 2006. Pedoman Peyelenggaraan Prosedur Rekam Medis Rumah Sakit di Indonesia. Direktorat Jendral Bina Pelayanan Medik. Revisi II. Jakarta.

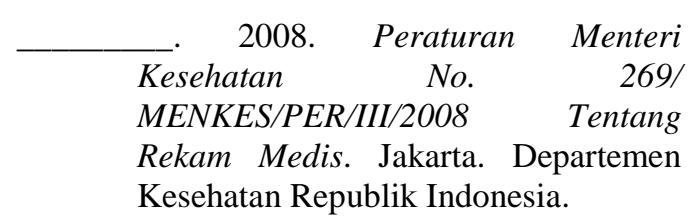

Dorlands, WAN. 2012. Kamus Saku Kedokteran Dorland. Edisi 28. Jakarta : EGC.

Heriyanto. 2011. Analisis Kuantitatif Dokumen Rekam Medis Pasien Carcinoma Mamae Pada Triwulan IV Tahun 2010 Di Unit Rawat Inap RSUD Dr. Moewardi Surakarta. [KTI]. Karanganyar: STIKes Mitra Husada Karanganyar.

Notoatmodjo S. 2010. Metodologi Penelitian Kesehatan. Jakarta. Rineka Cipta.

Sjamsuhidajat, R. Wim de Jong. 2011. Buku Ajar Ilmu Bedah, Edisi Ketiga. Jakarta : EGC 
Jurnal Manajemen Informasi dan Administrasi Kesehatan (J-MIAK)

Volume 01, No 01, Tahun 2018

ISSN: 2621-6612

Email: d3perinfokesunivet@gmail.com

Halaman: 1-10

Sudra RI. 2013. Rekam Medis. Jakarta : Universitas Terbuka

Sugiyono. 2010. Statistik Untuk Penelitian. Bandung: Alfabeta

Sujarwo T. 2011. Analisis Kuantitatif Pada Dokumen Rekam Medis Pasien Laparotomy Di Unit Rawat Inap Bangsal Dalam Rumah Sakit Umum
Daerah Kota Salatiga Periode Tahun 2010. [KTI]. Karanganyar: STIKes Mitra Husada Karanganyar.

Wahyuni. 2011. Analisis Kuantitatif Dokumen Rekam Medis Dengan Diagnosis Tuberculosis Paru Triwulan I Tahun 2010 Di Unit Rawat Jalan BBKPM Surakarta. [KTI]. Karanganyar: STIKes Mitra Husada Karanganyar. 